\title{
Caries Prevalence in Children and Adolescents of German-Speaking and Non- German-Speaking Parents, Who Underwent Scheduled Dental General Anesthesia in Innsbruck, Austria. A twelve-year retrospective study
}

\author{
Dagmar Schnabl ${ }^{1, *}$, Annachiara Guarda ${ }^{1}$, Maria Guarda ${ }^{1}$, Lia Marie von Spreckelsen ${ }^{1}$, Marina Riedmann², René Steiner ${ }^{1}$, \\ Johannes Laimer ${ }^{3}$ and Herbert Dumfahrt ${ }^{1}$
}

\begin{abstract}
${ }^{1}$ University Hospital of Dental Prosthetics and Restorative Dentistry, Medical University of Innsbruck, Innsbruck, Austria ${ }^{2}$ Department of Medical Statistics, Informatics and Health Economics, Medical University of Innsbruck, Innsbruck, Austria ${ }^{3}$ University Hospital of Cranio-Maxillofacial and Oral Surgery, Medical University of Innsbruck, Innsbruck, Austria
\end{abstract}

*Corresponding author: Dagmar Schnabl, University Hospital of Dental Prosthetics and Restorative Dentistry, Medical University of Innsbruck, Innsbruck, 6020, Austria, Tel: +43 512504 27162; Fax: +43 512504 27157; E-mail: dagmar.schnabl@tirol-kliniken.at

Received: 24 Nov, 2018 | Accepted: 14 Dec, 2018 | Published: 20 Dec, 2018

Citation: Schnabl D, Guarda A, Guarda M, von Spreckelsen LM, Riedmann M, et al. (2018) Caries Prevalence in Children and Adolescents of German-Speaking and Non-German-Speaking Parents, Who Underwent Scheduled Dental General Anesthesia in Innsbruck, Austria. A twelve-year retrospective study. Int J Dent Oral Health 5(1): dx.doi.org/10.16966/2378-7090.283

Copyright: (c) 2018 Schnabl D, et al. This is an open-access article distributed under the terms of the Creative Commons Attribution License, which permits unrestricted use, distribution, and reproduction in any medium, provided the original author and source are credited.

\begin{abstract}
Objectives: Caries polarization is a common problem in industrialized countries. Ethnic minority status, poor educational attainment, and low socioeconomic status have been shown to be inversely associated with oral health care and outcomes worldwide. The aim of this retrospective study in children and adolescents, who underwent scheduled dental general anesthesia (comprising restorative therapy and tooth extractions), was to investigate, if a migratory background impacts childhood caries prevalence in the federal state of Tirol, Austria.

Methods: 1,703 consecutive cases of children and adolescents ( $\leq 16$ years), who were (due to dental anxiety or mental and/or physical disablement or disease) unamenable to treatment under local anesthesia, received scheduled dental general anesthesia at the University Hospital of Innsbruck in the years 2003 to 2014. From digital patient files, personal and demographic data (including age, gender, and parents' language affiliation - Germanspeaking/non-German-speaking) were collected. From preoperative orthopantomograms, numbers of previously filled teeth were obtained. Numbers of carious teeth restored and of profoundly carious teeth extracted under dental general anesthesia were recorded. Data analysis was performed by means of descriptive and comparative statistics.

Results: Children/adolescents of non-German-speaking parents required significantly more tooth extractions than those of German-speaking parents ( $4.11 \pm 3.20$ vs $5.22 \pm 3.25$ ), whereas differences in previously filled teeth and in teeth restored under general anesthesia were not significant between the two subgroups.

Conclusions: Children/adolescents treated under dental general anesthesia presented high caries prevalence and a severe backlog in oral health. Within the collective, prevalence of profound caries was higher in children/adolescents of non-German-speaking parents. Intensified prophylactic measures (including education in oral hygiene/nutrition and information on the benefit of regular dental consultations) specifically addressing marginalized groups at high caries risk should be implemented in order to increase oral health literacy.
\end{abstract}

Keywords: Dental general anesthesia; Childhood caries; Caries prevalence; Ethnicity

\section{Introduction}

Dental caries presents one of the most important oral global health burdens and has a major impact on health-related quality of life [14]. Oral health surveys based on WHO criteria [5] have illustrated a decline of caries prevalence in industrialized Western European countries over the past 40 years as a result of public health measures $[2,6]$. This is also the case in Austria, where the mean d $3 \mathrm{mft}$ score in the WHO target group of six-year-old children was 4.2 in 1996 and 2.1 in 2011 [7,8]. In the federal state of Tirol, six-year-olds presented mean $\mathrm{d} 3 \mathrm{mft}$ scores of 1.0 in the year 2006 and of 0.7 in the year 2011
[7,9]. Furthermore, in 2011, absence of caries ( $\mathrm{d} 3 \mathrm{mft}=0)$ was assessed in $74 \%$ of Tirolean six-year old children in 2011 (and in 52\% of sixyear-olds from all over Austria) $[8,9]$. In Germany, for comparison, $54 \%$ of six-year-old children were caries-free according to a survey in the year 2009 [10]. Although in the state of Tirol, the WHO goal for the year 2020 [11] of $80 \%$ caries-free six-year-old children was almost reached already in the year in 2011 [9], the concentration of all caries in one fourth of all six-year-olds indicates a polarization in high risk groups. A low level of education and a migratory background (MB) have thereby been identified as risk factors [8]. Children in need for dental general anesthesia (DGA) certainly belong to the share of 
children at high caries risk. At the University Hospital of Innsbruck (the main hospital center in Tirol), upon referral by dental practitioners or pediatricians, scheduled DGA is performed in uncooperative or medically compromised/disabled non-pain children diagnosed with carious lesions.

This retrospective study aimed the assessment of caries prevalence in the population of children and adolescents, who received scheduled DGA, in the context of demographic factors. The null hypothesis was that there is no difference in caries prevalence between children/ adolescents of German-speaking and those of non-German-speaking parents within the study collective of individuals living and being educated in Tirol, Austria.

\section{Materials and Methods}

\section{Subjects}

1,703 consecutive cases of scheduled DGA at the University Hospital of Innsbruck, from January 1st 2003 to December 31st 2014, in patients aged $\leq 16$ years served as study population. The cohort consisted of non-pain patients (suffering neither acute nor enduring pain), who were unamenable to dental treatment under local anesthesia due to dental anxiety or intellectual and/or physical disablement or disease. Uncooperative children without disablement/illness were registered for DGA only upon presentation of a mandatory referral form consigned by a dentist in practice containing information that standard dental treatment was impossible. At their first visit, the children's medical, dental and family history was taken, a clinical assessment was made as well as contrivable, and an orthopantomogram (OPG) was taken, if possible and not already provided by the referring dentist. Upon informed parents' consent, patients were scheduled for DGA. After a pre-operative assessment of suitability for anesthesia at the outpatient clinic of the Department of Anaesthesiology and Critical Care Medicine, DGA was performed on a day-unit basis. Under intubation anesthesia, after professional cleaning and examination, carious teeth (with lesion extension into dentin) were restored with composite fillings and profoundly carious teeth (displaying vital or non-vital pulp exposition on excavation) were extracted. At the Hospital of Innsbruck, endodontic treatment is not performed during DGA in order to keep duration of general anesthesia as short as possible and to avoid postoperative complications that might necessitate further treatment under DGA. Admission to DGA and dental treatment were carried out by changing consultants on duty according to the guidelines described above.

\section{Study design and data acquisition}

The study was conceived as a retrospective analysis of anonymized personal data (including demographic information and the absence/ presence of disablement) and treatment performed under DGA, in order to correlate caries prevalence with demographic factors. The study was carried out in accordance with the Declaration of Helsinki and ethical approval was obtained by the institutional ethical committee, study number AN2014-0269 341/4.8 (3621a).

The following data were extracted from electronic patient files, coded by numbers, and listed in a table (Excel, Microsoft, Redmond, WA, USA):
a) Date of birth
b) Gender male/female
c) Parents' or single parents first language: German-speaking (G)/ non-German-speaking (NG)

d) Intellectual and/or physical disablement or disease yes/no

e) Date of DGA

f) $O P G$ yes/no

g) Preexisting fillings in primary or permanent teeth, derived from existing OPGs

h) Restorative treatment under DGA in primary or permanent teeth, assigned to teeth and surfaces

\section{i) Primary or permanent teeth extracted under DGA}

Ad a) and e) From date of birth and date of DGA the patients' age at the time of DGA was calculated.

Ad c) With a similar cultural background and conception of oral health within the neighboring German-speaking countries Germany, Switzerland, and South Tirol (Italy) presumed, only children of NG immigrants were of interest in this study. Parents answered the language question at registration for DGA.

Ad d) The diagnosis "intellectual and/or physical disablement" was available from medical reports or referral letters

Ad f) and g) Only OPGs of good quality, taken shortly before or at the day of registration, were evaluated by one experienced examiner with regard to teeth with preexisting fillings. Fillings were assigned to teeth only, but not to certain tooth surfaces.

\section{Data analysis}

Basic demographic data was analyzed by means of descriptive statistics. Numerical data were reported as mean \pm standard deviation (SD) and categorical data were summarized as absolute and relative frequencies. Shapiro-Wilk test was used to assess the normality of data distribution. For the comparative analysis of not normally distributed data in subgroups, Mann-Whitney U test was used. Significance level was set at $\mathrm{p}=0.05$. All calculations were performed in SPSS software (SPSS Statistics Version 21, IBM, Armonk, NY, USA).

\section{Results}

\section{Subjects}

Mean age of all children at the time of DGA was $5.6 \pm 2.53$ years (range one to 16 years). Out of a total of 1,703 children, $966(56.7 \%)$ were male and 737 (43.3\%) were female. 983 children (57.7\%) had G parents and 720 children (42.3\%) had NG parents. In 185 children (10.9\%), intellectual and/or physical disablement was recorded.

\section{OPG}

A preoperative OPG of good quality was available in 1,088 children $(63.9 \%)$.

\section{Previously filled teeth}

The mean number of previously filled primary and permanent teeth was $0.65 \pm 1.37$ in children/adolescents with OPG $(n=1,088)$. Differences in numbers of previously filled teeth were statistically neither significant between boys and girls (Table 1) nor between children/adolescents of G and NG parents (Table 2).

\section{Restorative treatment under DGA}

In the total collective $(n=1,703), 9,591$ teeth (assigned to 16,476 tooth surfaces; $37.2 \%$ of which occlusal, $20.4 \%$ buccal, $16.5 \%$ mesial, $13.1 \%$ lingual, and $12.8 \%$ distal) were restored with composite fillings. 8,065 (84\%) restored teeth were primary and 1,526 (16\%) were permanent teeth. Per patient, $5.59 \pm 3.16$ teeth received restorative 
Table 1: Previously filled teeth; restored and extracted teeth under DGA, by gender.

\begin{tabular}{|c|c|c|}
\hline & Males (n=965) \\
\hline Previously filled teeth per patient* Mean \pm SD & $0.66 \pm 1.41^{\mathrm{a}}$ \\
\hline Restored teeth under DGA per patient Mean \pm SD & $5.61 \pm 3.19^{\mathrm{b}}$ \\
\hline Extracted teeth under DGA per case Mean \pm SD & $0.6 \pm 1.29^{\mathrm{a}}$ & $5.57 \pm 3.13^{\mathrm{b}}$ \\
\hline \multicolumn{2}{|c|}{$4.61 \pm 3.32^{\mathrm{c}} \pm 3.23^{\mathrm{c}}$} \\
\hline
\end{tabular}

DGA: dental general anesthesia; SD: standard deviation; “*based on orthopantomograms"; males ( $n=610)$, females ( $n=478)$ ${ }^{a} \mathrm{p}=0.994 ;{ }^{b} \mathrm{p}=0.569 ;{ }^{c} \mathrm{p}=0.838 ;$ Mann-Whitney U test

Table 2: Previously filled teeth; restored and extracted teeth under DGA, by parents' language affiliation.

\begin{tabular}{|c|c|c|}
\hline & G (n=983) & NG (n=720) \\
\hline Previously filled teeth per patient* Mean \pm SD & $0.71 \pm 1.47^{\mathrm{a}}$ & $0.57 \pm 1.23^{\mathrm{a}}$ \\
\hline Restored teeth under DGA per case Mean \pm SD & $5.55 \pm 3.28^{\mathrm{b}}$ & $5.65 \pm 2.98^{\mathrm{b}}$ \\
\hline Extracted teeth under DGA per case Mean \pm SD & $4.11 \pm 3.20^{\mathrm{c}}$ & $5.22 \pm 3.25^{\mathrm{c}}$ \\
\hline
\end{tabular}

DGA: dental general anesthesia; G: German-speaking; NG: non-German-speaking; SD: standard deviation; “*based on orthopantomograms”; G ( $=616$ ), NG $(n=472)$

${ }^{a} p=0.413 ;{ }^{b} p=0.132 ;{ }^{c} p<0.001 ;$ Mann-Whitney U test

therapy. Differences in numbers of restored teeth were not significant between the subgroups of gender and language affiliation (Tables 1,2).

\section{Tooth extractions under DGA}

In the total sample ( $\mathrm{n}=1,703), 7,803$ teeth were extracted, 7,478 (95.8 $\%)$ of which were primary and 325 (4.2\%) of which were permanent teeth. Per patient, $4.58 \pm 3.27$ teeth were extracted.

While no statistically significant difference in numbers of extracted teeth was found between boys and girls (Table 1), the difference in tooth extractions between children/adolescents of G and NG parents was highly significant (Table 2).

\section{Discussion}

In Austria and worldwide, low socioeconomic status, poor educational attainment, and ethnic minority status (frequently in combination) have been shown to be inversely associated with oral health care and outcomes [8,12-17]. In the years 2003 to 2014, most immigrants from NG countries were coming from successor states of former Yugoslavia and from Turkey. The two groups constituted 18.6\% and $12.3 \%$, respectively, of all persons of foreign nationality living in Tirol (2014) [18]. Foreign G and NG nationalities together constituted $13.1 \%$ (2014) and ex-Yugoslavian and Turkish people (adults and children) together constituted around $5 \%$ of the total population in 2004 and $4 \%$ in 2014, respectively [18]. Regarding these proportions, the share of $42.3 \%$ children/adolescents of NG parents was remarkably high in the study sample. As expected, in the selection of children/ adolescents afflicted with dental anxiety and/or disablement/ systemic disease (10.9\%), prevalence of carious lesions in need for treatment was disastrously high. Within the collective, children/ adolescents of NG parents required significantly more extractions of profoundly carious primary teeth than those of $\mathrm{G}$ parents did. It seems that some parents seek dental consultation only in the presence of evident decay. The low number of previously filled teeth $(0.65 \pm$ 1.37) in the study sample reflects a poor utilization of dental care institutions and/or the children's/adolescents' non-amenability to routine treatment. The results of the present study indicate an urgent need for improvement of oral health literacy and oral care. In Tirol, a statewide public educational program on oral health is carried out by avomed (working group for preventive medicine and health promotion) [7]. "It includes regular oral health screenings (followed by a referral to a dental consultation, if necessary) and teachings in kindergartens and schools, which are designed to raise awareness for dental hygiene and a healthy lifestyle. Despite these dedicated efforts, some social groups have so far been insufficiently accessed. Thereby, a low social standard, a poor perception of general/oral health, and language barriers may be causative factors. Anywhere in Tirol, access to dental care providers is available within a reasonable distance. Still, prophylactic routine dental consultations seem to be rarely utilized by marginalized population groups. DGA, in contrast, appears to be considered an "easy solution". DGA requires high efforts in terms of personnel and financial expenditure [19] and implicates the risk of anesthetic complications [20]. Even so, improved treatment conditions under DGA have been shown to yield better outcomes in terms of a higher quality of restorations as compared to alternative approaches [21-23]. In Austria, the costs for DGA in public hospitals are (like the costs for treatment by panel dentists) borne by the statutory public health insurance system. Alternatives such as behavior management, hypnodontia, conscious sedation/nitrous oxide analgesia, or DGA in private practice are subject to private payment and hardly utilized by the clientele presenting at the University Hospital of Innsbruck.

In summary, children/adolescents in need for DGA presented high caries prevalence and a severe backlog in oral health. Within the collective, prevalence of profound caries was higher in the offspring of NG parents. The null hypothesis was rejected.

Limitations to this study are owed to its retrospective character. Calibration of multiple operators could not be assured. However, all operators were obliged to comply with the hospital's strict guidelines in patient admission, diagnosis, and treatment as described above. Information on the parents' socioeconomic situation or on the provenance of immigrants was not available from patient files and thus not taken into consideration in the analysis. Further studies using a prospective design should include possible confounding factors such as the parents' educational level and socioeconomic parameters. 


\section{Conclusion}

In order to equalize oral health levels within the general population, educational and prophylactic measures specifically addressing marginalized groups at high caries risk should be implemented. Caries prophylaxis in the infant should thereby begin with counseling and treatment of the expectant mother and individual or group prophylaxis should start with the care of the child's first teeth [24-27]. Parents should be enjoined to adhere to regular dental attendance for their children.

\section{Acknowledgements}

The study was supported by the University Hospital of Dental Prosthetics and Restorative Dentistry of Innsbruck, Austria.

\section{Conflicts of Interest}

The authors declare that there are no conflicts of interest in this study.

\section{References}

1. Pitts NB, Zero DT, Marsh PD, Ekstrand K, Weintraub JA, et al. (2017) Dental caries. Nat Rev Dis Primers 3: 17030.

2. Petersen PE (2005) The burden of oral disease: challenges to improving oral health in the 21st century. Bull World Health Organ 83: 3.

3. Leal SC, Bronkhorst EM, Fan M, Frencken JE (2012) Untreated cavitated dentine lesions: impact on children's quality of life. Caries Res 46: 102-106.

4. Haag DG, Peres KG, Balasubramanian M, Brennan DS (2017) Oral conditions and health-related quality of life: A systematic review. $J$ Dent Res 96: 864-874.

5. World Health Organisation (2013) Oral health surveys; basic methods-5th edition. School of Dentistry, University of São Paulo, Brazil.

6. Petersson GH, Bratthall $D$ (1996) The caries decline: a review of reviews. Eur J Oral Sci 104: 436-443.

7. Luckner-Hornischer A, Halder-Kessler $M$, Erber-Kuprian $A$, Holzhammer G (2009) Zahnstatusbericht Sechsjährige mit und ohne Migrationshintergrund Tirol 2006. Amt der Tiroler Landesregierung, Innsbruck.

8. Bodenwinkler A, Kerschbaum J, Sax G (2012) Zahnstatus 2011 Sechsjährige in Österreich. Gesundheit Österreich GmbH, Vienna.

9. Gesundheit Österreich GmbH (2012) Zahngesundheit. In: Tiroler Gesundheitsbericht. Amt der Tiroler Landesregierung, Innsbruck 114-115.

10. Pieper K (2009) Epidemiologische Begleituntersuchungen zur Gruppenprophylaxe 2009. Deutsche Arbeitsgemeinschaft für Jugendzahnpflege, Bonn.

11. Hobdell M, Petersen PE, Clarkson J, Johnson N (2003) Global goals for oral health 2020. Int Dent J 53: 285-288.
12. Wagner $Y$, Greiner S, Heinrich-Weltzien R (2014) Evaluation of an oral health promotion program at the time of birth on dental caries in 5-year-old children in Vorarlberg, Austria. Community Dent Oral Epidemiol 42: 160-169.

13. Berkowitz RJ (2003) Causes, treatment and prevention of early childhood caries: a microbiologic perspective. J Can Dent Assoc 69: 304-307.

14. Uribe $S$ (2009) Early childhood caries--risk factors. Evid Based Dent 2009 10: 37-38.

15. Seow WK, Clifford H, Battistutta D, Morawska A, Holcombe T (2009) Case-control study of early childhood caries in Australia. Caries Res 43: 25-35.

16. Schwendicke F, Dörfer CE, Schlattmann P, Foster Page L, Thomson WM, et al. (2015) Socioeconomic inequality and caries: a systematic review and meta-analysis. J Dent Res 94: 10-18.

17. Da Rosa P, Rousseau MC, Edasseri A, Henderson M, Nicolau B (2017) Investigating socioeconomic position in dental caries and traumatic dental injury among children in Quebec. Community Dent Health 34: 226-233.

18. Dobler C, Kaiser M (2015) Demographische Daten Tirol 2014. Amt der Tiroler Landesregierung, Sachgebiet Landesstatistik und tiris, Innsbruck.

19. Rashewsky S, Parameswaran A, Sloane C, Ferguson F, Epstein R (2012) Time and cost analysis: Pediatric dental rehabilitation with general anesthesia in the office and the hospital settings. Anesth Prog 59: 147-153.

20. De Francisci G, Papasidero AE, Spinazzola G, Galante D, Caruselli M, Pedrotti et al. (2013) Update on complications in pediatric anesthesia. Pediatr Rep 5: e2.

21. Eidelman E, Faibis S, Peretz B (2000) A comparison of restorations for children with early childhood caries treated under general anesthesia or conscious sedation. Pediatr Dent 22: 33-37.

22. Karim ZA, Musa N, Noor S (2008) Utilization of dental general anaesthesia for children. Malays J Med Sci 15: 31-39.

23. Blumer S, Costa L, Peretz B (2017) Success of dental treatments under behavior management, sedation and general anesthesia. J Clin Pediatr Dent 41: 308-311.

24. Günay H, Dmoch-Bockhorn K, Günay Y, Geurtsen W (1998) Effect on caries experience of a long-term preventive program for mothers and children starting during pregnancy. Clin Oral Investig 2: 137-142.

25. Mileva SP, Kondeva VK (2010) Age at and reasons for the first dental visit. Folia Med (Plovdiv) 52: 56-61.

26. Wagner $Y$, Heinrich-Weltzien $R$ (2017) Risk factors for dental problems: Recommendations for oral health in infancy. Early Hum Dev 114: 16-21.

27. Mahat G, Bowen F (2017) Parental knowledge about urban preschool children's oral health risk. Pediatr Nurs 43: 30-34. 